\title{
Opening and closure forces of sliding mechanisms of different self-ligating brackets
}

\author{
Paola GANDINI ${ }^{1}$, Linda ORSI ${ }^{2}$, Maria Francesca SFONDRINI ${ }^{3}$, Andrea SCRIBANTE ${ }^{4}$
}

\author{
1-MD, DDS, Professor and Chairman, Unit of Orthodontics, Department of Clinical, Surgical, Diagnostic and Pediatric Sciences, School of Dentistry, University \\ of Pavia, Pavia, Italy. \\ 2- DDS, Postgraduate fellow, Unit of Orthodontics, Department of Clinical, Surgical, Diagnostic and Pediatric Sciences, School of Dentistry, University of \\ Pavia, Pavia, Italy. \\ 3- MD, DDS, PhD, Professor, Unit of Orthodontics, Department of Clinical, Surgical, Diagnostic and Pediatric Sciences, School of Dentistry, University of \\ Pavia, Pavia, Italy. \\ 4- DDS, PhD, MHA, Research resident, Unit of Orthodontics, Department of Clinical, Surgical, Diagnostic and Pediatric Sciences, School of Dentistry, University \\ of Pavia, Pavia, Italy.
}

Corresponding address: Andrea Scribante - University of Pavia - Poliambulatorio di Odontostomatologia - Reparto di Ortognatodonzia - Piazzale Golgi 2 27100 - Pavia - Italy - e-mail: andrea.scribante@unipv.it

Received: January 14, 2013 - Modified: February 28, 2013 - Accepted: March 20, 2013

\section{ABSTRACT}

\begin{abstract}
Self-ligating brackets engage the wire by means of a slide mechanism. Forces that have $\checkmark$ to be applied to open and close the sliding mechanism of brackets are still unknown. Objective: The aim of this study was to measure and compare the opening and closure forces of different self-ligating brackets. Material and Methods: Three different stainless steel self-ligating brackets (Carriere LX, Ortho Organizers; F1000, Leone; Damon Q, Ormco) were tested. For each different bracket, 20 maxillary right central incisors and 20 mandibular right central incisors were used. Opening and closure forces were measured using an Instron Universal Testing Machine. Statistical analysis was performed and ANOVA and Tukey tests were carried out. Results: Opening forces were registered between $1.1 \mathrm{~N}$ and $5.6 \mathrm{~N}$, whereas closure forces were recorded between $1.57 \mathrm{~N}$ and $4.87 \mathrm{~N}$. Significant differences were detected among the different brackets and between the two prescriptions tested. Conclusion: The knowledge of different opening and closure forces of self-ligating brackets can help the orthodontist in the clinical management of these devices.
\end{abstract}

Key words: Biomaterials. Biomechanics. Friction. Orthodontics. Orthodontic brackets.

\section{INTRODUCTION}

With their advantages and defects, self-ligating orthodontic brackets have presented an increased diffusion in orthodontic practice in the last 10 years ${ }^{8}$

Various aspects of self-ligating brackets have been studied in order to evaluate their properties and characteristics. Frictional forces $6,7,9$, torque expression ${ }^{2,10}$, rotation capacity ${ }^{12}$, bond strength ${ }^{21,22}$, and reconditioning procedures ${ }^{23}$ have been tested. Moreover, clinical researches have also been carried out to evaluate bonding ${ }^{5}$ and the periodontal parameters ${ }^{13}$.

Obtaining adequate force during orthodontic treatment will certainly result in an optimal tissue response and satisfactory tooth movement ${ }^{4}$. Higher treatment speed claimed using self-ligating brackets can be reduced from many factors, such as early accidental de-bonding, bracket breakage or damage to the bracket wicket ${ }^{3,8}$. In order to avoid bracket damages or detachments, forces that have to be applied to open and close the wicket that engage the wire inside the bracket should be known. This data would help the clinicians when managing these devices. In fact, insufficient opening and closure forces do not allow wicket sliding movements, whereas excessive pressure on the wicket can detach or damage the bracket.

To our knowledge there are no studies in the literature that measured the opening and closure forces of the self-ligating brackets sliding mechanism.

Accordingly, the aim of the present investigation was to measure and compare the opening and closure forces of three different self-ligating 
brackets. The null hypothesis of the study was that there are no significant difference force values among the various groups.

\section{MATERIAL AND METHODS}

Three different stainless steel pre-adjusted self-ligating brackets were tested: Carriere LX (Ortho Organizers, Carlsbad, California, USA), F1000 (Leone, Sesto Fiorentino, Italy), and Damon Q (Ormco, Glendora, California, USA). For each different bracket, 20 maxillary right central incisors and 20 mandibular right central incisors were used.

Each specimen was bonded to a plastic support that was then fixed in the lower jaw of an Instron Universal Testing Machine (Model 3365, Instron Industrial Products, Grove City, PA USA).

To evaluate the opening forces of the wickets, a specifically designed bar with a terminal hook was fixed to the upper part of the testing machine (Figure 1). The edge of the hook was inserted in the hole of the wicket of a closed bracket. The hook was then moved upward in a vertical direction at
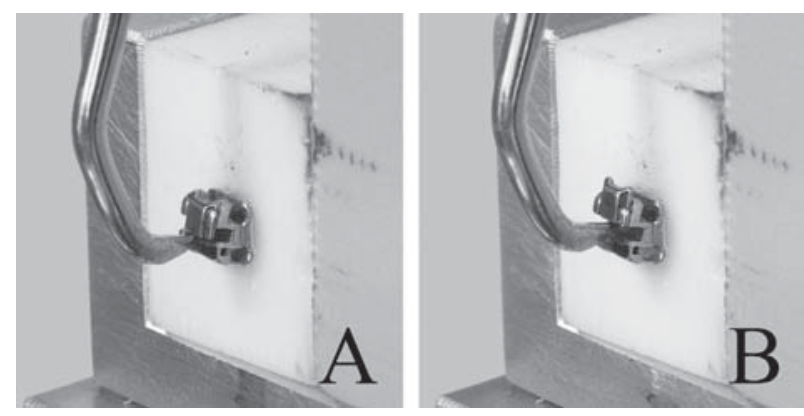

Figure 1- Testing apparatus for opening force measurement (A: position before test; $B$ : position after test) a crosshead speed of $1 \mathrm{~mm}$ per minute until the bracket was completely opened. Maximum opening force value $(\mathrm{N})$ was recorded for each specimen.

To evaluate the closure forces of the wickets, a specifically designed bar with a terminal flat plane was fixed to the upper part of the testing machine (Figure 2). The flat plane of the bar was leaned to the upper edge of the wicket of an opened bracket. The bar was then moved downward in a vertical direction at a crosshead speed of $1 \mathrm{~mm}$ per minute until the bracket was completely closed. Maximum closure force value (N) was recorded for each specimen.

A statistical analysis was performed. Normality of the data was assessed with the KolmogorovSmirnov test. Subsequently ANOVA and Tukey tests were carried out. The significance was predetermined at $P<0.05$.

\section{RESULTS}

Descriptive statistics for the opening and closure forces $(\mathrm{N})$ of the different brackets are illustrated
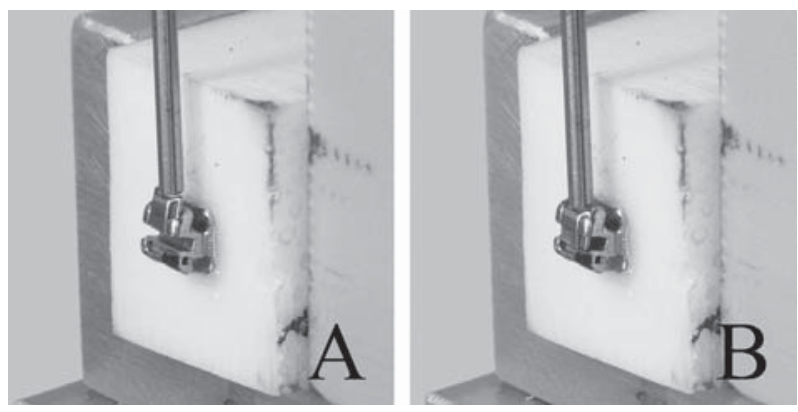

Figure 2- Testing apparatus for closure force measurement (A: position before test; B: position after test)

Table 1- Descriptive statistics of the different brackets tested $(\mathrm{N})$. All groups showed normal distributions

\begin{tabular}{cccccccccc}
\hline Group & Bracket & Prescription & Movement & Mean & SD & Min & Mdn & Max & Tukey* \\
\hline 1 & Carriere LX & Upper central incisor & Opening & 3.34 & 0.12 & 3.2 & 3.3 & 3.7 & $\mathrm{~A}$ \\
2 & Carriere LX & Upper central incisor & Closure & 4.42 & 0.11 & 4.29 & 4.4 & 4.71 & B \\
\hline 3 & F1000 & Upper central incisor & Opening & 5.46 & 0.07 & 5.3 & 5.5 & 5.6 & C \\
4 & F1000 & Upper central incisor & Closure & 3.87 & 0.31 & 3.32 & 3.89 & 4.53 & D \\
\hline 5 & Damon Q & Upper central incisor & Opening & 4.89 & 0.35 & 4.4 & 4.8 & 5.5 & E \\
6 & Damon Q & Upper central incisor & Closure & 4.68 & 0.11 & 4.45 & 4.68 & 4.87 & E \\
7 & Carriere LX & Lower cental incisor & Opening & 1.41 & 0.18 & 1.1 & 1.4 & 1.8 & F \\
8 & Carriere LX & Lower cental incisor & Closure & 2.28 & 0.1 & 2.12 & 2.28 & 2.46 & G \\
\hline 9 & F1000 & Lower cental incisor & Opening & 3.28 & 0.38 & 2.7 & 3.3 & 3.9 & A \\
10 & F1000 & Lower cental incisor & Closure & 1.8 & 0.32 & 1.57 & 1.69 & 2.85 & H \\
11 & Damon Q & Lower cental incisor & Opening & 2.81 & 0.09 & 2.7 & 2.8 & 3 & I \\
12 & Damon Q & Lower cental incisor & Closure & 2.49 & 0.16 & 2.02 & 2.56 & 2.6 & G \\
\hline
\end{tabular}

*Tukey grouping. Means with the same letters are not significantly different 
in Table 1. Data of all groups showed normal distributions. The analysis of variance showed the presence of significant differences among the various groups $(P<0.0001)$. When analyzing the Carriere LX brackets, a post-hoc test showed that the opening force is significantly lower than the closure force $(P<0.001)$, both for the upper and lower central incisor prescriptions. On the contrary, the $\mathrm{F} 1000$ brackets demonstrated an opening force significantly higher than the closure force $(P<0.001)$, both for the upper and lower central incisor prescriptions. Finally, the Damon $\mathrm{Q}$ brackets showed no significant differences between the opening and closure force when testing the upper central incisor prescription $(P>0.05)$. On the contrary, for the lower central incisor, the Damon $\mathrm{Q}$ opening forces were significantly higher than the closure forces $(P<0.001)$.

Moreover, for all the three different devices tested, the upper central incisor bracket showed significantly higher forces than the lower central incisor bracket, both for the opening and closure movements $(P<0.0001)$.

\section{DISCUSSION}

The null hypothesis of the study has been rejected. The different self-ligating brackets showed opening forces between $3.2 \mathrm{~N}$ and $5.6 \mathrm{~N}$ for the right central upper incisor prescription and between $1.1 \mathrm{~N}$ and $3.9 \mathrm{~N}$ for the right central lower incisor prescription. The F1000 showed significantly higher opening forces than the other brackets for both prescriptions tested. The lowest forces were recorded with the Carriere LX brackets both for the upper and lower right central incisor prescriptions.

Closure forces were recorded between 3.32 $\mathrm{N}$ and $4.87 \mathrm{~N}$ for the right central upper incisor prescription and between $1.57 \mathrm{~N}$ and $2.85 \mathrm{~N}$ for the right central lower incisor. When testing the maxillary right central incisor, the Damon Q showed significantly higher closure forces than the other brackets; the lowest forces were recorded with the F1000. For the mandibular right central incisor, the Carriere LX and Damon Q showed no significant differences between them and both exhibited significantly higher closure forces than the F1000.

The great technological advancements that have occurred in the last years have brought researchbased findings that have constantly led to the development of new materials and techniques ${ }^{15}$. These improvements are claimed to simplify the clinical procedures, but many commercially available orthodontic materials have been experimentally evaluated in laboratories ${ }^{17}$ but not all aspects were tested to confirm their efficiency and effectiveness. Despite the various characteristics of self-ligating brackets that have been evaluated ${ }^{16}$, to date in the literature there are no studies that evaluated the opening and closure forces of different self-ligating brackets. When analyzing single brackets, in the present study, the Carriere LX opening force was significantly lower than the closure force, both for the upper and lower central incisor prescriptions. On the contrary, the F1000 brackets demonstrated an opening force significantly higher than the closure force, both for the upper and lower central incisor prescriptions. Finally, the Damon Q brackets showed no significant differences between the opening and closure force when testing the upper central incisor prescription, whereas when testing the lower central incisor, the Damon Q opening forces were significantly higher than the closure forces.

Moreover, in the present investigation the upper central incisor brackets showed significantly higher forces than the lower central incisor brackets, both for the opening and closure movements for all the three different devices tested.

This variability of values means that the force applied to open or close a bracket is different, tooth by tooth, also when using the same appliance type. This is probably due to the different bracket shape and size. The clinician should consider this data when approaching the patient. In fact, the evaluation of the opening and closure forces necessary to allow the slide of the mechanism is necessary because discomfort is a potential side effect during fixed appliance orthodontic therapy ${ }^{18,19}$. This can negatively influence the desire to undergo treatment ${ }^{11}$, compliance ${ }^{20}$, and treatment outcome ${ }^{14}$. For this reason opening and closure forces should not be excessive in order to reduce discomfort when changing the archwire or reactivating the appliance. On the other side, after closure, the wicket should remain locked until the following orthodontic visit, leaving the wire secured to the bracket and allowing the appliance to express tooth movement.

Some limitations were raised in the present pilot study. First of all this investigation has been conducted under ideal laboratory conditions, whereas in the oral cavity the presence of saliva, plaque, corrosion and other variables can influence the wicket sliding movement ${ }^{16}$. Moreover, clinical experience suggests that a mechanistic view of orthodontics is misleading and so selfligating brackets and their peculiar characteristics are only a component of orthodontics. Among other things, orthodontics deals with science, evidence, psychosocial issues, record taking, diagnoses, treatment, treatment outcomes, artistry, enhancements, and quality-of-life issues ${ }^{1}$. The findings of the present study, within their extents, suggest further researches in order to analyze all variables and quantify and appraise the real influence of opening and closure forces on the 
clinical use of self-ligating brackets.

\section{CONCLUSIONS}

\section{This study demonstrated the following:}

The different self-ligating brackets showed opening forces between $3.2 \mathrm{~N}$ and $5.6 \mathrm{~N}$ for the right central upper incisor prescription and between $1.1 \mathrm{~N}$ and $3.9 \mathrm{~N}$ for the right central lower incisor prescription with significant differences among them.

Closure forces were recorded between 3.32 $\mathrm{N}$ and $4.87 \mathrm{~N}$ for the right central upper incisor prescription and between $1.57 \mathrm{~N}$ and $2.85 \mathrm{~N}$ for the right central lower incisor prescription with significant differences among the different brackets tested.

Upper central incisor brackets showed significantly higher forces than the lower central incisor bracket, both for the opening and closure movements

\section{ACKNOWLEDGEMENTS}

The Authors wish to thank Leone, the Ormco and Ortho Organizers for providing the materials tested in this study.

\section{REFERENCES}

1- Ackerman M, Rinchuse DJ, Rinchuse DJ. ABO certification in the age of evidence and enhancement. Am J Orthod Dentofacial Orthop. 2006;130:133-40

2- Badawi HM, Toogood RW, Carey JP, Heo G, Major PW. Torque expression of self-ligating brackets. Am J Orthod Dentofacial Orthop. 2008;133:721-8.

3- Chalgren R, Combe EC, Wahl AJ. Effects of etchants and primers on the shear bond strength of a self-ligating esthetic orthodontic bracket. Am J Orthod Dentofacial Orthop. 2007;132:577.e1-5.

4- Cunha AC, Marquezan M, Freitas AO, Nojima LI. Frictional resistance of orthodontic wires tied with 3 types of elastomeric ligatures. Braz Oral Res. 2011;25:526-30.

5- Elekdag-Turk S, Cakmak F, Isci D, Turk T. 12-month self-ligating bracket failure rate with a self-etching primer. Angle Orthod. 2008; 78:1095-100

6- Franchi L, Baccetti T, Camporesi M, Barbato E. Forces released during sliding mechanics with passive self-ligating brackets or nonconventional elastomeric ligatures. Am J Orthod Dentofacial Orthop. 2008;133:87-90
7- Gandini P, Orsi L, Bertoncini C, Massironi S, Franchi L. In vitro frictional forces generated by three different ligation methods. Angle Orthod. 2008;78:917-21.

8- Harradine NW. Self-ligating brackets: where are we now? J Orthod. 2003;30:262-73.

9- Matarese G, Nucera R, Militi A, Mazza M, Portelli M, Festa F, et al. Evaluation of frictional forces during dental alignment: an experimental model with 3 non-leveled brackets. Am J Orthod Dentofacial Orthop. 2008;133:708-15.

10- Morina E, Eliades T, Pandis N, Jäger A, Bourauel C. Torque expression of self-ligating brackets compared with conventional metallic, ceramic, and plastic brackets. Eur J Orthod. 2008;30:233-

11- Oliver RG, Knapman YM. Attitudes to orthodontic treatment. $\mathrm{Br}$ J Orthod. 1985;12:179-88.

12- Pandis N, Eliades T, Partowi S, Bourauel C. Moments generated during simulated rotational correction with self-ligating and conventional brackets. Angle Orthod. 2008;78:1030-4.

13- Pandis N, Vlachopoulos K, Polychronopoulou A, Madianos P, Eliades T. Periodontal condition of the mandibular anterior dentition in patients with conventional and self-ligating brackets. Orthod Craniofac Res. 2008;11:211-5.

14- Patel V. Non-completion of active orthodontic treatment. $\mathrm{Br}$ ] Orthod. 1992:19:47-54

15- Pithon MM, Oliveira MV, Ruellas AC, Bolognese AM, Romano FL. Shear bond strength of orthodontic brackets to ename under different surface treatment conditions. J Appl Oral Sci. 2007; 15:127-30.

16- Rinchuse DJ, Miles PG. Self-ligating brackets: present and future. Am J Orthod Dentofacial Orthop. 2007;132:216-22.

17- Romano FL, Correr AB, Correr-Sobrinho L, Magnani MB, Ruellas AC. Clinical evaluation of the failure rates of metallic brackets. J Appl Oral Sci. 2012;20:228-34

18- Scheurer PA, Firestone AR, Bürgin WB. Perception of pain as a result of orthodontic treatment with fixed appliances. Eur J Orthod. 1996;18:349-57.

19- Scott P, Sherriff M, Dibiase AT, Cobourne MT. Perception of discomfort during initial orthodontic tooth alignment using a selfligating or conventional bracket system: a randomized clinical trial. Eur J Orthod. 2008;30:227-32

20- Sergl HG, Klages U, Zentner A. Functional and social discomfort during orthodontic treatment - effects on compliance and prediction of patients' adaptation by personality variables. Eur J Orthod. 2000;22:307-15.

21- Sfondrini MF, Gatti S, Scribante A. Effect of blood contamination on the shear bond strength of orthodontic brackets and disinclusion buttons. Br J Oral Maxillofac Surg. 2011;49:404-8. 22- Sfondrini MF, Gatti S, Scribante A. Shear bond strength of self-ligating brackets. Eur J Orthod. 2011;33:71-4.

23- Sfondrini MF, Xheka E, Scribante A, Gandini P, Sfondrini G. Reconditioning of self-ligating brackets. Angle Orthod. 2012;82:158-64. 